Dearborn Observatory for 1883 . The 18 -inch Alvan Clark equatorial has again been employed in clcse ot servation of the great red spot and other thenomena of the planet Jupiter. Since the first observations at Chicago in September, 1879 , it is stated that the red spot had not changed very materially in length, breadih, outline, or latitude. There had been a slow, retrograde drift in longitude, causing an apparent increase in the time of axial rotation. At the last opposition the deduced mean-rotation pericd was $9 \mathrm{~h} .55 \mathrm{~m} .38 \cdot 4 \mathrm{~s}$. against $9 \mathrm{~h} .55 \mathrm{~m} .34^{\circ} 8 \mathrm{~s}$. in 1879 .

Prof. Hough gives the following mean results of micrometrical measures of the red spot:-

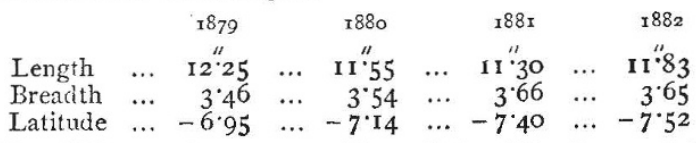

The Chicago observer considers that while the spot has remained nearly stationary in latitude, the south edge of the great equatorial belt has gradually drifted south during the late oppo:ition, untsl it is nearly coincident with the middle of the spot, and further, that "the two do not blend together, but are entirely distinct and separate." A depression formed in the edge of the belt (as shown in two drawings of the planet's disk, on December 29, 1882, and February 20, 1883), which corresponded in shape with the oval outline of the spot, the distance between the two being about a second of arc. The spot was extremely faint at the last observation for longitude on May 5 . The equatorial white spot, first observed in 1879 , was again visible during the last opposition; the rotation period $9 \mathrm{~h} .5 \mathrm{Om}$. $9 \cdot 8 \mathrm{~s}$. deduced in the previous year, satisfying the observations.

The great comet of 1882 was micrometrically measured from October 4 to November 20 , and sketches of the nucleus and envelope made. Subsequently to October 6 three centres of condensation were usually visible. As the comet receded from the sun, the head increased in length from $25^{\prime \prime}$ on October 4 to I $39^{\prime \prime}$ on November 20. As late as March 6 there appeared to be three centres of condensation connected by matter of less density.

Difficult double-stars bave been measured by Prof. Hough and Mr. S. W. Burnham, amongst them the interesting binaries, 40 Eridani $(\Sigma 5$ I 8 ), $\beta$ Delphini, $\delta$ Equulei, and 85 Pegasi. Measures of the companion of Sirius gave for the epoch I883.12 position $39^{\circ} .9$, distance $9^{\prime \prime} \cdot 04$; the distance is diminishing about $0^{\prime \prime} \cdot 3$ annually, so that in a few years it will be beyond reach of any except the largest telescopes. With the excellent measures obtained at Chicago more must soon be known as to the period of $\delta \mathrm{Equulei,}$ reputed the most rapid of all binaries.

TEMPEL's COMET, 1873 II.-The following are places for Greenwich midnight, deduced from M. Schulhof's elements:-

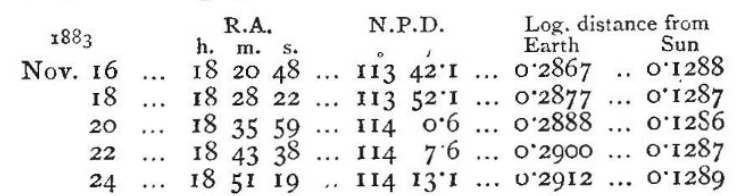

This comet approaches pretty near to the orbit of the planet Mars; in heliocentric longitude $312^{\circ}$ (equinox of 1878 ), corresponding to true anomaly $6^{\circ} \cdot \mathrm{r}$, the distarice is $0^{\circ} 05^{\circ}$.

D'ARREST'S ComeT.-M. Leveau's ephemeris of this comet terminates on November 25 . The following places are reduced from it to $6 \mathrm{~h}$. Greenwich M.T. :-

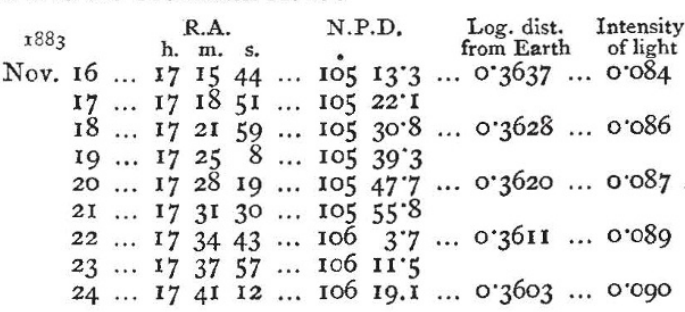

M. Leveau mentions that when Prof. Julius Schmidt last observed the comet at Athens in 1870 with a refractor of $0^{\circ} 17 \mathrm{~m}$. aperture the intensity of light was $0^{\circ} 150$.
On November 16 the comet sets at Greenwich $2 \mathrm{~h}$. Iom. af the sun.

The planetary perturbations during the next revolution are $\mathrm{r}$ likely to be large, so that in 1890 the comet may be observ under similar conditions to those of 1870 .

\section{STANDARD RAILROAD TIME}

THE following letter, addressed to our American conte porary Science, is of interest :-

Though the subject of standard and uniform railway time 1 for some years been under consideration by various scientific a practical bodies, it does not appear in any way to have be exhausted, even in its main features. Besides, a certain bi bas shown itself in favour of the adoption of a series of cert hourly meridians, and thus keeping Greenwich minutes a seconds, when contrasted with the practicability of a more sim proposition. There is also a feature in the discussion of $t$ ] subject which bears to have more light thrown upon it : namel what necessary connection there is between the railway compani uniform time and the mean local time of the people, or the tir necessarily used in all transactions of common life. Directly by implication, certain time-reformers evidently aim at a standa. time, which shall be alike binding on railw ay traffic as well as the business community; and to this great error much of $t$ complexity of the sutject is to be attributed, and it has direct retarded the much-needed reform in the time-management our roads.

We say all ordinary business everywhere must for ever be co ducted on local mean solar time, the slight difference betwe apparent and mean time having produced no inconvenience and we may rightly ask the railway companies to give in the time-tables for public use, everywhere and always, the mean loc time of the departure and of the arrival of trains. It is $t$ departure from this almost self-evident statement, and the su stitution and mixing-up in the time-tables of times referred various local standards, which has in no small measure cont buted to the confusion and perplexity of the present syster The people at large do not care to know by what time-syste any railroad manages its trains, any more than they care wh the steam-pressure is, or what is the number of the locomotiv All the traveller is interested in is regularity and safety travel; hence it was to be desired that, whatever the standa or standards of time adopted, the companies would refrain fro: troubling bim with a matter which only concerns their intern organisation, or which is entirely administrative. We loo upon the publication of the railway time-tables, by local tim everywhere, as a sine quâ non for the satisfactory settlement the time question, so far as the public at large is concerned; an it would seem equally plain that the best system for the as ministration of railroads would be the adoption of a unifor time, this time to be known only to the managers and employ of the roads.

We are informed in Science of October 12 that the solution c the problem of standard railway time is near at hand, an probably has already been consummated by the adoption of for or more regions, each having uniform minutes and seconds c Greenwich time, but the local hour of the middle meridian. T have come down from several dozen of distinct time-sy:tems to very few and uniform ones, except as to the hour, is certainly step forward, and, so far, gratifying ; but why not adopt Greer wich time, pure and simple, and have absolute uniformity Probably this will be felt before long. The counting of twent four hours to the day in the place of twice twelve, and the oblitera tion from time tables of the obnoxious a.m. and p. m. numbers would seem to be generally acknowledged as an improvemen and simplification, and perhaps can best be dealt with $b$ adopting it at once, accompanied by a simple explanator statement.

Washington, October 18

\section{UNIVERSITY AND EDUCATIUNAL INTELLIGENCE}

OXFORD. - No election has yet taken place either for th Professorship of Botany or that of Rural Eiconomy, which ari now separated from each other. The Delegates of the Commor University Fund have agreed to attach á Readership to the Chai of Botany, which will raise the income to 500l. a year. Thi 
Professorship of Rural Economy will not be a resident one. The Professor will have to deliver twelve lectures. His stipend is $200 l$. a year.

\section{SOCIETIES AND ACADEMIES LONDON}

Mathematical Society, November 8.-Prof. Henrici, F.R.S., president, in the chair.-The following resolution, proposed by the President and seconded by Dr. Hirst, F.R.S., was carried unanimously, viz. :- "That the secretaries be requested to communicate to Mrs. Spottiswoode the expression of our sincere sympathy and the assurance of our deep sense of the loss which science has sustained by the untinely death of $\mathrm{Mr}$. Spottiswoxde." - The new Council was elected for the session I883-84, viz. : Prof. Henrici, president ; Sir J. Cockle, F.R.S., and Mr. S. Roberts, F.R.S., vice presidents; Mr. A. B. Kempe, F.R.S., treasurer; Messrs. M. Jenkins and R. Tucker, honorary secretaries; other members, Pr..f. Cayley, F.R.S., Messrs. E. B. Elliott, J. W. L. Glai-her, F.R.S., J. Hammond, H. Hart, Dr. Hirst, F.R.S., W. D. Niven, F.R.S., Prof. Rowe, and Messrs. R. F. Scott and J. J. Walker, F.R.S. The Rev. J. J. Mylne and Mr. F. W. Watkin were elected members. -The following papers were communicated:-Symmetric functions, and in particular on certain inverse operators in connection therewith, Capt. P. A. Macmahon.-On a certain envelope, Prof. Wolstenholme. - On certain results obtained by means of the arguments of points on a plane curve, R. A. Rıberts.-Third paper on multiple Frullanian integrals, E. B. Elliott.-Note on Jacobi's transformation of elliptic functions, J. Griffiths.-Symmedians and the triplicate-ratio circle, $R$. Tucker.

Linnean Society, November I.-Frank Crisp, treasurer and vice-president, in the chair.-Messrs. T. E. Gunn and A. Hutton were elected Fellows.-A donation to the Society of several interesting letters of Linnæus $(1736-1769)$ to G. N. Ehret, F.R.S., an eminent botanical artist of the last century, was announced by the Chairman, and a unaminous vote of thanks thereupon accorded to the Misies Grover and Mr. Chas. Ehret Grover for their valuable donation.-Mr. Crisp drew attention to specimens in fluid inedium of Limnocodium sowerbii, as illustrative of Mr. P. Squires' method of preserving delicate and other medusæ. - Mr. H. Groves sh wed examples of Chard braunii from Ashton-under-Lyne, and Mr. Arthar Bennett of Najas marina and $N$. alagnensis from Hickling Broad, Norfolk, al being new to the British flora.-Mr. W. Fawcett exbibited Testacella maugei alive, the same being o'tained ny J. C. Mansel Pley. dell in Dorset, and supposed to be indiyenous to that county.-A paper was read on the changes of the flora and fauna of New Zealand, by Dr. S. M. Curl. He referred more particularly to the district of Rangitikei and to the alterations of the aspect of the vegetation within the last forty years. He likewive records his own experiments in the cultivation of trees, shrubs, and flowering plants introduced from widely different climes, remarking that while a few fail to grow with vigour, the majority by degrees adapt themselves to the altered $\mathrm{c}$,nditi $n \mathrm{n}$, and many valuable economic plants thrive accordingly.-Mr. J. Starkie Gardner read a paper on Alnus richardsoni, a fo sil fruit from the London Clay of Herne Bay. The species has been described by Bowerbank and commented on by Carruthers, Ettinghausen, and many other auth rs who have written upon the plants of the Tertiary formation. Orıinally considered as allied to Casuarina, Dr. R. Brown suggested its affinities to the Proteaceæ, a view afterwards upheld by Carruthers and others. Ettinghausen thereafter regarded it as a product of a Conifer (Sequoia), and Saporta compared the fruit to that of Dammara. Mr. Gardner enters fully into the structural peculiarities of the fossil fruit in question, and sati-factorily demonstrates that it belongs to the Betulaceæ under the genus Alnus. -Another paper by Miss G. Lister was read, viz. on the origin of the Placentas in the tribe Alsinex of the order Caryophyllex. This communication is based on a series of ubservations on the development of a number of genera and pecies. She concludes that the capsule in the Alsinex i; developed on essentially the same plan as that of Lychnis, the difference in the various genera being merely dependent upon the relative height attained by the carpels on the one hand, and by the central axis on the other. This being so, we are bound to admit that if we accept, as we do, the carpellary origin of the placentas i: Lychnis, the placentas in the Alsinex, from Sagina apetaia, wh:ch nost resemble
Lychnis, to Cerastium triviale, which most widely differs from it, are also carpellary.

Chemical Society, November I.-Dr. Perkin, F.R.S., president, in the chair. - The f llowing papers were read :-On the production of hydroxylamine from nitric acid, by E. Divers. Free nitric acid yields hydroxylamine when treated with tin, zinc, cad nium, magnesium, and aluminium. In the presence of hydrochloric or sul phuric acid the quantity with tin or zinc may be con-iderable. Without a second acid only traces can be detected. The author also discusses the action of nitric acid upon metals and the constitution of nitrites, in which he considers the metal to be directly united with nitrogen.-On the chemistry of lacquer (Urushi) (part i.), by H. Yoshida. Lacquer contains a peculiar acid, Urushic acid, extracted by alcohol, some gum resembling gum arabic, water, and a peculiar diastatic body containing nitrogen. The lacquer when exposed to moi it air at $20^{\circ} \mathrm{C}$. dries up into a hard lustrous varnish. This hardening is brought about by the action of the diastase upon Urushic acid, the latter heing converted intn oxy-urushic acid.-On some compounds of phenols with amidobases, by G. Dyson. The author has prepared and investigated anilin phenate, toluidin phenate, naphthylamin phenate, anilin $\beta$ naphthate, toluidin naphtnate, rosanilin phenate, xylidin naphthate, rosanilin aurinate, anilin aurinate.-On the alleged decomposition of phosphorous anhy dricle by sunlight, by R. Cowper and V. B. Lewes. In a paper at the British Association, Southport, the Rev. A. Irving stated that phosphorou: anhydride prepared by passing air over heated phosuhorus is decrmposed by sunlight into phosphorus and phosphoric anhydride. The authors find that phosphorous anhydricle thus prepared consists of a mixture of phosphoric anhydride, phosphorous anhydride, and phosphorus.

Physical Society, November ro.-Prof. Clifton in the chair.-Dr. J. Blaikley read a paper on the velocity of sound in air, in which he described a modification of Dulong's method of measuring it by the wave-length in a pipe lengthened. Dulong did not allow for the partial tones, which are an important factor, whereas Mr. Blaikley does. By means of organ pipes of different diameters, the author has found the velocity to be about 320 metres per second. Mean result with four tubes: one of $54^{\prime} \mathrm{I} \mathrm{mm}$. diameter, velocity $=3^{2} 9^{\circ} 73$ metres per second ; one of $32.5 \mathrm{~mm}$. diameter, velocity $=328.78$ metres; one of $19^{\circ} 5 \mathrm{~mm}$. diameter, velocity $=326.9$ metres; one of $\mathrm{II}^{\prime} 7 \mathrm{~mm}$., velocity $=324.56$ metres. The velocity diminishes as the tube is smaller in bore.-Mr. Bosanquet made a communication on the moment of a compound magnet, which he showed how to measure by the method already published by him. A compound magnet made up of eighteen small cylinders of magnetised steel placed end to end is hung in a cradle carried by a delicate bifilar suspension, and placed at right angles to the magnetic meridian. The deviation from zero produced by the magnet is noted; then the magnet is divided into two parallel rows of nine cylinders along the cradle, and the deviation again noted. The tangent of the angle of deviation from the east and west line, multiplied by a constant, is the moment of the magnet. The author also pointed out that to define the condition of a permanent magnet it was necessary to know the difference of magnetic potential, the "resistance" of the metal, and the resistance of the external space. - Mr. W. Lant Carpenter read a paper on measurements relating to the electric resistance of the skin, and certain medical appliances. The author's experiments, made upon himself, showed that the resistance of the body amounts to thousands of ohms, but is mainly due to the condition of the epidermis. If this is dry, the resistance is high By soaking the skin in salt and water, he reduced the resistance of parts of his body from Io, $300 \mathrm{ohms}$ to $935 \mathrm{ohms}$ after 100 minutes' soaking. He infers that a large electrode should be used in applying electricity to the body, and that the skin should be soaked for twenty-five minutes previously. Mr. Carpenter also exhibited a "chainband" of Mr. Pulvermacher, and a small voltameter by the same inventor, in which the liberated gases force some of the water up a graduated tube as a gauge of the current. The author drew at ention to the necessity of seeing that the skin should be dry in handling some electric light machines, else disagreeable shocks might result. Prof. Ayrton believed that the danger of electric lighting currents lay rather in their discontinvity than their electromotive force. The Brush currents, which have proved fatal, are more discontinu is than those of the Gramine machine, \&c. Adverting to the presence of electricity in the air as influencing health, he suggested that the 